Table 1

Mean Persuasion Scores by Sex of Subject, Agree vs Disagree Conditions, and Hunger (using the Hours since Last Food Measure)

\begin{tabular}{llcccc}
\hline & & \multicolumn{2}{c}{ Males } & \multicolumn{2}{c}{ Females } \\
& & N & Mn & N & Mn \\
\hline \multirow{3}{*}{ Hungry } & Agree & 26 & 18.23 & 33 & 17.97 \\
& Disagree & 13 & 18.46 & 23 & 19.39 \\
\multirow{3}{*}{ Not Hungry } & Agree & 24 & 17.89 & 34 & 19.38 \\
& Disagree & 18 & 19.88 & 28 & 18.36 \\
\hline
\end{tabular}

the agree condition and more under the disagree condition than nonhungry Ss.

Results and Discussion

The sole main effect of sex was that, counter to Study 1, males were more variable on time since last food intake $(F=1.67, \mathrm{df}=80,107, \mathrm{p}<.01)$.

Table 1 shows the mean persuasion scores by sex, agree vs disagree conditions, and hunger, using the measure of time since last food intake (coded as in Study 1 and divided by a median split). Table 2 shows the same data using the self-report hunger measure (divided into very or moderately vs slightly or not at all).

For both analyses of variance, interactions between hunger and agree vs disagree were nil $(F<1)$ for males. For females, they were in the expected directions and approached significance $(F=3.80, p<.06$, using the self-report measure; $F=2.40$, $\mathrm{p}<.15$, using the time measure; $\mathrm{df}=1,104$ for both). The three-way interaction terms for these effects were: $F=2.08, p<.15$, using self-report; $F=2.20, p<.10$ using time; $\mathrm{df}=1,181$ for both.

Considering both studies, although no single analysis permits a firm conclusion, the patterns of results with the two paradigms are quite congruent and provide a strong suggestion that for females only hunger produced less compliance with $\mathrm{E}$ demands on a persuasion test.

One possible explanation for the sex specificity of this relationship is based on a finding by Silverman (1967) using the same $S$ population as the present studies, that females, to a greater extent than males, tended to acquiesce more to a persuasive message when it was presented in the context of a psychological experiment than when it was not. This suggested that females, more than males, respond to persuasion tests in terms of their demand characteristics.

Table 2

Mean Persuasion Scores by Sex of Subject, Agree vs Disagree Conditions, and Hunger (Using the Self-report Measure)

\begin{tabular}{llrcccc}
\hline & & \multicolumn{2}{c}{ Males } & \multicolumn{2}{c}{ Females } \\
& & N & Mn & N & Mn \\
\hline \multirow{3}{*}{ Hungry } & Agree & 19 & 18.68 & 20 & 17.45 \\
& Disagree & 9 & 19.78 & 11 & 20.18 \\
Not Hungry & Agree & 25 & 17.64 & 37 & 19.16 \\
& Disagree & 28 & 19.25 & 40 & 18.45 \\
\hline
\end{tabular}

The present data may offer some resolution of the paradoxical findings of Dabbs and Janis, although their $S$ sample described as "Yale College students" was probably male. It is a feasible conjecture, however, that the extent to which Ss respond to the demands of a particular experimental paradigm varies, not only between sexes within the same population, but among different student populations.

\section{REFERENCES}

CATALDO, J. F., SILVERMAN, I., \& BROWN, J. M. Demand characteristics associated with semantic differential ratings of verbs and nouns. Educational Psychological Measurement. $1967,27,83-87$.

DABBS, J. M., \& JANIS, I. Why does eating while reading facilitate opinion change?-An experimental inquiry. Journal of Experimental Social Psychology, 1965, 2, 133.

JANIS, I. L., KAYE, D., KIRSCHNER, P. Facilitating effects of "eating-while-reading" on responsiveness to persuasive communications. Journal of Personality \& Social Psychology, $1965,1,181-185$.
ORNE, M. On the social psychology of the psychological experiment: With particular reference to demand characteristics and their implications. American Psychologist, 1962, 17 , 776-783.

ROSENTHAL, R. Experimenter effects in behavioral research. New York: AppletonCentury-Crofts, 1966.

SILVERMAN, I. Role-related behavior of subjects in laboratory studies of attitude change. Joumal of Personality \& Social Psychology, 1968, 8, 343-348.

SILVERMAN, I., FORD, L. H., \&ORGANTI, J. B. Inter-related effects of social desirability, sex, selfesteem, and complexity of argument on persuasability. Joumal of Personality, 1966, 34, 555-568.

SILVERMAN, I., \& KLEINMAN, D. A response deviance interpretation of experimentally induced frustration on prejudice. Joumal of Experimental Research in Personality, 1967, 2, 150-153.

\section{NOTE}

1. This study was supported by Grant No. GS-1945 from the National Science Foundation to the first au thor.

\title{
Retrieval cues and meaningfulness in short-term recall
}

\section{THOMAS O. NELSON, ${ }^{1}$ University of Illinois, Urbana, Ill. 61801}

The effect of retrieval cues ( $R C$ s) on the short-term recall of CCC items was explored. Three types of RCs were used: facilitative (correct letter), interfering (wrong letter), and neutral (no letter). It was hypothesized that the effect of RCs would be accentuated with high-meaningfulness (M) items and attenuated with low-M items. Forty-two college Ss were individually run through 36
Peterson short-term memory trials. Although the main effects of both $R C$ and $M$ were significant, the $R C$ by $M$ interaction was not significant, contrary to prediction.

Category names as retrieval cues (RCs) have been shown to facilitate free recall (e.g., Tulving \& Osler, 1968). Loess \& Harris (1968) demonstrated that categoryname RCs can facilitate the short-term recall of word triads. The present study 
used CCC items and had one of the three serial positions filled in during recall. Three types of RCs were used: facilitative cue (FC) which had the same letter as was originally presented filled in (e.g., if the original item had been " $B \mathrm{C} D$ " then the FC might be "B _ _"); interfering cue (IC) which had an incorrect letter filled in (e.g., given " $B$ C D" the IC might be "W neutral cue (NC) with no letter filled in (e.g., given "B C D" the NC might be "* _ "). The NC provided a baseline upon which the effects of FC and IC could be assessed. The predicted ease of recall given each RC was FC, NC, IC.

Martin (1968, p. 421) states that "Iow-M stimuli are viewed as more fractionable, less integrated than are high-M stimuli." This generally held view is also suggested by Shepard (1963, p. 59) and Melton (1963, p. 306). Peterson, Peterson, \& Miller (1961) provided empirical evidence by showing that the probability of recalling the $n+1$ th letter of a CCC, given that the $n^{\text {th }}$ letter had been correctly recalled, increased with meaningfulness. Therefore, it was hypothesized that the effect of RCs would be accentuated as meaningfulness of the CCC increased.

\section{METHOD}

The Ss were 42 undergraduates from the University of Illinois. A Carousel projector presented the following Peterson \& Peterson (1959) sequence: READY signal (2 sec), CCC $(1.5 \mathrm{sec})$, retention interval $(15 \mathrm{sec})$, and recall interval $(8 \mathrm{sec})$. The $18 \mathrm{high}-\mathrm{M}$ CCCs had a Witmer (1935) association value of 83.5 while the 18 low-M CCCs had a mean of 15.0. The items had the following properties: The same two letters never appeared together in the same positions in more than one item and never appeared next to each other in more than one item; the consonants $M, N, V, W$, and $Y$ never appeared in any items; each of the remaining 16 consonants appeared either 6 , 7 , or 8 times in the entire series of 36 items.

There were two item orders. The first was completely random except that no item contained the same letter as the preceding item, regardless of letter position. The second order was an inversion of the first and high-M items were replaced by low-M items (and vice versa) with the assignment of items being random except that no item received the same type of $R C$ as it had in the first order. Similarly there were two orders of $\mathrm{RCs}$, random except for the following restrictions: No RC-type appeared in the same letter position more than three times in succession; each RC-type appeared six times with high- $M$ items and six times with low-M items, twice at each of the three letter positions.

The ICs were always the letters $M, N, V$, and $W$ (each appeared only once at each letter position). Using ICs which were not in the letter pool that generated the $\mathrm{CCC}$ items

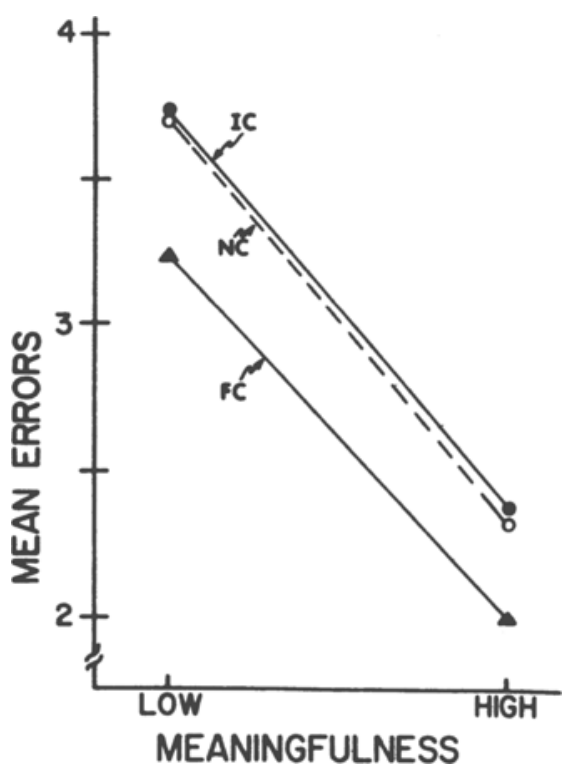

Fig. 1. Mean number of errors as a function of type of retrieval cue (facilitative cue, neutral cue, or interfering cue) and level of meaningfulness. (Note: Each point is based on six possible successes from each of $42 \mathrm{Ss}$.)

insured that the interference would be general (as opposed to specific); this prevented differential specific interference from prior items. Three nonexperimental CCCs were added to the beginning of the list to minimize differential proactive inhibition.

The $S$ read each item aloud during acquisition, and number reading filled the retention interval. During recall, $S$ read the $R C$ aloud and tried to fill in the two missing letters, guessing if necessary; the NC was read aloud as "star."

\section{RESULTS}

The dependent variable was the number of errors, where an error was defined as failure to recall both of the two missing letters in their correct serial positions. The results were analyzed in a four-way analysis of variance with order (two levels) as a between-S variable; $M$ (two levels), RC-type (three levels), and RC position (three levels) were within-S variables. The mean number of errors for all Ss, pooled over item orders and RC positions, in each $M$ by RC condition is shown in Fig. 1. Low-M items were more difficult to recall than high-M items, $F(1,40)=142.73, p<.01$. RC-type was a significant variable, $F(2,80)=4.24$, $\mathrm{p}<.025$, but the only significant difference was that $\mathrm{NC}$ and IC were more difficult than FC; IC was not significantly more interfering than NC. The M by RC-type interaction did not approach significance, $F(2,80)<1$, and Fig. 1 shows that the three curves are nearly parallel, contrary to prediction.
The only remaining significant differences were for item order, $F(1,40)=7.22$, $\mathrm{p}<.025$, and $\mathrm{M}$ by RC-position, $\mathrm{F}(2,80)=3.53, \mathrm{p}<.05$ (this reached significance because the number of errors increased at the third-letter position for high-M items but decreased for low-M items). It is curious that the RC-position main effect was not significant, $F(2,80)=1.01$.

\section{DISCUSSION}

The most bewildering finding was that RC-type did not interact significantly with $M$. This would have been understandable if either the RC-type or M main effects had also been nonsignificant, but both were significant (cf. the analogous result in Experiment 2 of Loess \& Harris, 1968). It may be that providing $S$ with a correct letter might not be sufficient for triggering the sequential-letter-dependency effect of high$\mathbf{M}$ items; perhaps $\mathbf{S}$ must himself generate the correct letter in order for this effect to become actualized in short-term recall.

An additional puzzling result was the failure to find an interference effect of IC, as compared with NC. Since the change rate of a Carousel projector is relatively slow (approximately $.5 \mathrm{sec}$ ), perhaps $S$ recalled the $\mathrm{CCC}$ as the number slide disappeared, and utilized the RC only when he failed in this initial attempt. Such a strategy would account for both the facilitative effect of FC and the lack of a significant difference between IC and NC.

\section{REFERENCES}

LOESS, H., \& HARRIS, R. Short-term memory for individual verbal items as a function of method of recall. Journal of Experimental Psychology, 1968, 78, 64-69.

MARTIN, E. Stimulus meaningfulness and paired-association transfer: An encoding variability hypothesis. Psychological Review, $1968,75,421.441$.

MELTON, A. W. Implications of short-term memory for a general theory of memory. Journal of Verbal Learning \& Verbal Behavior, 1963, 2, 1-21.

PETERSON, L. R., \& PETERSON, M. J. Short-term retention of individual verbal items. Journal of Experimental Psychology, 1959, 58, 193-198.

PETERSON, L. R., PETERSON, M. J., \& MILLER, A. Short-term retention and meaningfulness. Canadian Journal of Psychology, 1961 , 15, 143-147.

SHEPARD, R. N. Comments on Professor Underwood's paper. In C. N. Cofer and B. S. Musgrave (Eds.), Verbal behovior and learning. New York: McGraw-Hill, 1963.

TUIVING, E., \& OSLER, S. Effectiveness of retrieval cues in memory for words. Journal of Experimental Psychology, 1968, 77, 593-601. WITMER, L. R. The association-value of three-place consonant syllables. Journal of Genetic Psychology, 1935, 47, 337-360. NOTE

1. Gratitude is expressed to William $H$. Batchelder for his generous counsel and thoughtful suggestions throughout the entire investigation. 